\title{
Public reaction to the portrayal of the tobacco industry in the film The Insider
}

\author{
Helen G Dixon, David J Hill, Ron Borland, Susan J Paxton
}

Centre for Behavioural Research in Cancer Cancer Control Research Institute, Anti-Cancer Council Victoria, Victoria, Australia

H G Dixon

D J Hill

VicHealth Centre for Tobacco Control, Cancer Control Research Institute, Anti-Cancer Council Victoria

$\mathrm{R}$ Borland

Department of Psychology, School of Behavioural Science, Faculty of Medicine Dentistry \& Health

Sciences, The

University of

Melbourne,

Melbourne, Australia

S J Paxton

Correspondence to:

Helen Dixon, Centre for

Behavioural Research in

Cancer, Anti-Cancer Counci

of Victoria, 1 Rathdowne

Street, Carlton South,

Victoria, 3053, Australia

Helen.Dixon@accv.org.au.

Received 18 January 2001 and in revised form

30 April 2001. Accepted 24 May 2001

\begin{abstract}
Objectives-To assess public perceptions of the tobacco industry and behavioural intentions for tobacco use in response to watching the film The Insider.
\end{abstract}

Design-Self administered pre-film survey conducted immediately before viewing and post-film telephone survey conducted within 1-5 weeks of viewing.

Setting-Two commercial cinemas in Melbourne, Australia.

Subjects-323 cinema patrons were recruited before screening of target films. 182 watched The Insider, 141 watched Erin Brockovich.

Interventions-Subjects watched one of two films: The Insider which featured information about unethical conduct by the tobacco industry and negative information about the health effects of smoking, or the "control" film Erin Brockovich which had an analogous plot without anti-tobacco content.

Main outcome measures-Pre-film questionnaire: assessed movie viewing habits, demographic characteristics, smoking status, attitudes towards the tobacco industry, intentions for smoking. Postfilm questionnaire: assessed same attitudes and intentions plus questions on the film viewed and perceptions of smoking prevalence.

Results-266 (82\%) subjects completed the post-film survey. Attitudes toward the tobacco industry were unfavourable at baseline. Those who saw The Insider held more negative views of business conduct by the tobacco industry than those who saw Erin Brockovich, once pre-existing attitudes to the industry were controlled for. The Insider also appears to have promoted a short term reduction in intentions to smoke.

Conclusions-Results of this study suggest that if people were recurrently exposed to anti-tobacco content in movies there is potential for a more substantial and lasting impact on attitudes toward the tobacco industry and smoking.

(Tobacco Control 2001;10:285-291)

Keywords: tobacco industry; movies; intervention

This paper reports on a study exploring public reaction to a film containing anti-tobacco content-The Insider.

To date, most discussion surrounding tobacco and film has centred on "prosmoking" film content. Concerns have been raised about the high frequency and image enhancing manner in which smoking tends to be depicted in popular movies. ${ }^{1-7}$ Negative long term health effects associated with smoking are rarely depicted in entertainment media. ${ }^{89}$ Research supports the thesis that actors who smoke in movies may inadvertently promote smoking to youth audiences. ${ }^{10-12}$

Whereas producers of news and documentary are constrained by fact, fiction and drama are not bound in this way which enables these forms of discourse to perform social symbolic functions more directly than others. ${ }^{13}$ Historically movie depictions of tobacco use have enabled attractive, image enhancing roles of smoking to be created and disseminated en masse. Fearing the influence of these images, health activists have argued that the creators of such artifice owe it to the public to show some "true" depictions of smoking.

\section{A new image for tobacco}

Rice and Atkin ${ }^{14}$ argued that " ...the social and economic causes - such as government policies or corporate irresponsibility - of many of our social ills are rarely dealt with at those levels by the mass media in general or even in campaigns in particular" (p 380-1).

Yet in recent years media depiction of tobacco has confronted these issues. In the 1990 s, tobacco policy issues received considerable coverage in mainstream news media ${ }^{15}$ and previously confidential tobacco industry documents entered the public domain. ${ }^{16}{ }^{17}$ These documents revealed active efforts by the industry to conceal information on the negative health effects of smoking, ${ }^{18}$ forcing "the truth out of the shadows and into the public eye" (p 314). ${ }^{17}$ In the USA, media campaigns exposing tobacco industry manipulation have also been mounted..$^{19-21}$

The theme of tobacco industry corruption has now received attention in entertainment media. In late 1999 Michael Mann's film The Insider was released in cinemas throughout North America, then in 30 countries throughout South America, Europe, Australasia, Asia and the Middle East during 2000. ${ }^{22}$ The Insider is a thriller exposé on how a series of lies by the tobacco industry were finally exposed by investigative journalism. Russell Crowe stars as real life tobacco industry whistleblower Jeffrey Wigand, who lost his job and was later sued, after talking to the media about the industry's knowledge and exploitation of the addictiveness of nicotine despite public statements to the contrary.

Anti-tobacco activists welcomed the emergence of a movie that cast tobacco in a bad light, ${ }^{23}$ whereas the tobacco industry was concerned about the impact of this film on 
Table 1 Characteristics of subjects

\begin{tabular}{|c|c|c|c|c|}
\hline \multirow[b]{2}{*}{ Survey/date (2000) } & \multicolumn{2}{|l|}{ The Insider } & \multicolumn{2}{|l|}{ Erin Brockovich } \\
\hline & $\begin{array}{l}\text { Pre-film/ Fan } \\
27-F e b 1\end{array}$ & $\begin{array}{l}\text { Post-film/ Feb } \\
\text { 1-March } 8\end{array}$ & $\begin{array}{l}\text { Pre-film/April } \\
13-15\end{array}$ & $\begin{array}{l}\text { Post-film/ April } \\
\text { 18-May } 22\end{array}$ \\
\hline Total sample (n) & 182 & 154 & 141 & 112 \\
\hline \multicolumn{5}{|l|}{$\operatorname{Sex}^{\star}$} \\
\hline Male & $52 \%$ & $49 \%$ & $33 \%$ & $30 \%$ \\
\hline Female & $48 \%$ & $51 \%$ & $67 \%$ & $70 \%$ \\
\hline \multicolumn{5}{|l|}{ Age in years $\dagger$} \\
\hline $15-19$ & $4 \%$ & $4 \%$ & $15 \%$ & $17 \%$ \\
\hline $20-24$ & $21 \%$ & $19 \%$ & $21 \%$ & $20 \%$ \\
\hline $25-29$ & $25 \%$ & $24 \%$ & $19 \%$ & $18 \%$ \\
\hline $30-39$ & $28 \%$ & $29 \%$ & $21 \%$ & $22 \%$ \\
\hline $40-49$ & $10 \%$ & $12 \%$ & $15 \%$ & $16 \%$ \\
\hline $50-59$ & $5 \%$ & $5 \%$ & $5 \%$ & $3.5 \%$ \\
\hline $60+$ & $7 \%$ & $7 \%$ & $4 \%$ & $3.5 \%$ \\
\hline \multicolumn{5}{|l|}{ Highest education level NS } \\
\hline Primary & $0 \%$ & $0 \%$ & $1 \%$ & $2 \%$ \\
\hline Some high school & $3 \%$ & $3 \%$ & $4 \%$ & $4 \%$ \\
\hline School certificate & $7 \%$ & $8 \%$ & $8 \%$ & $9 \%$ \\
\hline All secondary school & $21 \%$ & $20 \%$ & $21 \%$ & $21 \%$ \\
\hline Trade certificate or diploma & $13 \%$ & $16 \%$ & $13 \%$ & $13 \%$ \\
\hline University or college degree & $56 \%$ & $53 \%$ & $53 \%$ & $51 \%$ \\
\hline \multicolumn{5}{|l|}{ Smoking status NS } \\
\hline Heavy smoker & $6 \%$ & $7 \%$ & $7 \%$ & $6 \%$ \\
\hline Light smoker & $6 \%$ & $6 \%$ & $10 \%$ & $7 \%$ \\
\hline Occasional smoker & $9 \%$ & $9 \%$ & $7 \%$ & $9 \%$ \\
\hline Ex-smoker & $13 \%$ & $13 \%$ & $6 \%$ & $5 \%$ \\
\hline Non-smoker & $66 \%$ & $65 \%$ & $70 \%$ & $73 \%$ \\
\hline
\end{tabular}

NS, non-significant effect for demographic variable between film conditions, $p>0.05$. *Significant difference in sex distribution between two film conditions, $\mathrm{p}<0.01$. † Significant difference in age distribution between two film conditions, $\mathrm{p}<0.05$.

their public image. ${ }^{24}$ Despite otherwise divergent agendas, the views expressed by health groups and the tobacco industry concerning images of tobacco in movies attest to a shared perception that entertainment media may have a persuasive impact on audiences-irrespective of the intent of the movie producers.

"David and Goliath" movie dramas about big business being at odds with the health of the community are not limited to the tobacco industry. In Steven Soderbergh's film Erin Brockovich, Julia Roberts plays a law clerk who battles a major public utilities company responsible for water contamination that causes devastating illnesses in the community. The presence of this movie in mainstream cinemas presented an opportunity to conduct a survey assessing public reaction to The Insider, alongside a survey of a "control" audience watching a film matched for genre, without anti-tobacco content. The study was conducted in Melbourne, Australia. While there has been less media coverage and community debate about tobacco industry tactics in Australia than in the USA, a recent population survey indicates that tobacco companies are already held in low regard by the Australian public. ${ }^{25}$

The aim of this study was to assess people's perceptions of the tobacco industry and their behavioural intentions for smoking in response to viewing the film The Insider. It was hypothesised that viewing a movie featuring corporate misconduct by the tobacco industry (that is, viewing The Insider) would lead to negative perceptions of the tobacco industry, compared to viewing a film which does not present such information. We were uncertain whether exposure to this film would transpose into an anti-smoking message. A secondary aim was to investigate public perceptions of smoking prevalence in films and in real life.

\section{Method}

SUBJECTS

Three hundred and eighty three cinema patrons were recruited in the foyers of two Melbourne cinemas before screenings of target films. However, because Erin Brockovich was released after The Insider, 55 (28\%) of the people recruited for Erin Brockovich reported that they had seen The Insider. As the manipulation of interest for this study was exposure to either one movie or the other, these cases were excluded from all analyses.

Table 1 lists the characteristics of the 323 subjects eligible for the study. One hundred and eighty two watched The Insider, and 141 watched Erin Brockovich. Subjects in the two film conditions had comparable education $\left(\chi^{2}=3.94, \mathrm{df}=5, \mathrm{p}=0.559\right)$ and smoking status $\left(\chi^{2}=6.52, \mathrm{df}=4, \mathrm{p}=0.164\right)$. However, among those who saw Erin Brockovich, there was a higher proportion of women $\left(\chi^{2}=12.13\right.$, $\mathrm{df}=1, \mathrm{p}<0.001)$ and subjects in the youngest age group $\left(\chi^{2}=16.33, \mathrm{df}=6, \mathrm{p}=0.012\right)$. The distribution of smokers compares fairly well to the general population, although non-smokers were overrepresented $\left(\mathrm{c} / \mathrm{f}^{26}\right)$. The proportion with tertiary education was also high $\left(\mathrm{c} / \mathrm{f}^{27}\right)$. In Australia, cinema attendance is more frequent among those of higher socioeconomic status $(\mathrm{SES})^{28}$ - the proportion of non-smokers in our sample may reflect the higher SES of our sample.

Two hundred and sixty six (82\%) subjects completed the post-film survey. The demographic profile of subjects at the post-film survey was comparable to that at the pre-film survey.

\section{MATERIALS}

Films

Subjects viewed The Insider or Erin Brockovich (control film). Erin Brockovich had a comparable subtext to The Insider (tale of whistle blower on industry cover up of the harmful health impact of their products on the community) without anti-tobacco content (table 2). ${ }^{2930}$ Both films were classified "M15+", meaning that patrons aged 15 years or under are not admitted to the film unless accompanied by a parent or adult guardian. ${ }^{31}$

\section{Questionnaires}

The pre-film questionnaire included multiple choice items assessing age, sex, highest level of completed education, smoking status (response options as per categories in table 1), frequency of watching movies in cinema, video and TV respectively (response options: $7=$ at least twice a week, $6=$ once a week, $5=$ every two weeks, $4=$ once a month, $3=$ every two to three months, $2=$ twice a year, $1=$ less often, adapted from Village cinemail registration form $^{32}$ ). Items on exercise, alcohol and industries other than the tobacco industry were also included to distract from the study's focus on tobacco and thereby minimise response bias. 
Table 2 Description of the two films, including total box office

\begin{tabular}{|c|c|c|}
\hline & The Insider & Erin Brockovich \\
\hline Director & Michael Mann & Steven Soderbergh \\
\hline Writer & Eric Roth, Michael Mann & Susannah Grant \\
\hline Studio & Touchstone & Universal \\
\hline Starring & Al Pacino, Michael Gambon, Rip Torn, Russell Crowe & Aaron Eckhart, Albert Finney, Julia Roberts \\
\hline Genre & Drama & Drama \\
\hline Running time & 158 Minutes & 131 minutes \\
\hline Censorship (Australian) & $\mathrm{M} 15+$ & $\mathrm{M} 15+$ \\
\hline Released in Melbourne & Wednesday 26 January 2000 & Thursday 13 April 2000 \\
\hline \multicolumn{3}{|l|}{ Box office total ${ }^{\star}$} \\
\hline Australia & AU $\$ 4.497 \mathrm{~m}(\mathrm{US} \$ 2.949 \mathrm{~m}, 26$ January 2000$)$ & AU $\$ 16.153 \mathrm{~m}$ (US $\$ 9.644 \mathrm{~m}, 13$ April 2000$)$ \\
\hline USA & US $\$ 28.965 \mathrm{~m}$ (23 April 2000$)$ & US $\$ 125.548 \mathrm{~m}$ (6 August 2000$)$ \\
\hline$U K$ & £1.396m (US $\$ 2.227 \mathrm{~m}, 26$ March 2000$)$ & $£ 10.237 \mathrm{~m}(\mathrm{US} \$ 15.284 \mathrm{~m}, 28$ May 2000$)$ \\
\hline Synopsis & $\begin{array}{l}\text { Jeffrey Wigand was a central witness in the } \$ 246 \text { billion tobacco settlement, } \\
\text { the most expensive case brought against an industry in US history. Wigand } \\
\text { (Russell Crowe), former head of research and development and a corporate } \\
\text { officer at Brown \& Williamson, was the ultimate insider. Meanwhile, Lowell } \\
\text { Bergman, investigative reporter and " } 60 \text { Minutes" producer, arranged a legal } \\
\text { defence team for Wigand and taped the famous Wallace interview with its } \\
\text { devastating testimony. However, before the segment could air, Bergman } \\
\text { would lose to a CBS corporate decision to kill it. Wigand would find himself } \\
\text { sued, targeted in a national smear campaign, divorced, and facing possible } \\
\text { incarceration. Wigand, having wagered so much and now unable to deliver his } \\
\text { testimony to the American people, and Bergman, trying to defeat the smear } \\
\text { campaign and force CBS to air the interview, are two ordinary people in } \\
\text { extraordinary circumstances. They find themselves in a fight from which no } \\
\text { one will emerge as he entered and nothing will be the same again. }\end{array}$ & $\begin{array}{l}\text { Based on true events, Julia Roberts stars as Erin } \\
\text { Brockovich who defies the odds by taking on and } \\
\text { defeating a major public utilities company. While working } \\
\text { as a file clerk in a small law firm, Erin stumbles upon a } \\
\text { cover-up involving contaminated water in a small desert } \\
\text { community which is causing devastating illnesses. } \\
\text { Infuriated by the deception, she convinces her boss } \\
\text { (Finney) to allow her to investigate. Although the local } \\
\text { citizens are initially leery of becoming involved, Erin's } \\
\text { brash manner and ability to speak to them clearly-and } \\
\text { compassionately—earns their trust. With over } 600 \\
\text { plaintiffs signed up, the unlikely duo go on to win the } \\
\text { largest settlement ever paid in a direct-action suit- } \$ 333 \\
\text { million. In the process, she reinvents her life. }{ }^{30}\end{array}$ \\
\hline Smoking content & Does not contain any images of people smoking. & $\begin{array}{l}\text { Erin Brockovich (played by Julia Roberts) smokes in one } \\
\text { prominent scene in the opening title sequence of the film. } \\
\text { There is a close up of her as she leans against a wall in the } \\
\text { street and exhales a big puff of smoke. She drops the } \\
\text { cigarette and we see her extinguish it with her stiletto } \\
\text { shoe. It comes in with the first piece of music and also } \\
\text { features the Julia Roberts title card and the Erin } \\
\text { Brockovich card. }\end{array}$ \\
\hline
\end{tabular}

*US\$ conversions based on exchange rate at date of film release for Australia, and date of box office total for UK.

In the pre-film and post-film surveys, subjects were required to rate people in a list of professions on "ethics and honesty" and "power" respectively. The list of professions consisted of politician, movie director, nurse, tobacco industry executive, scientist, TV reporter, and multinational food company executive. Responses to these items were assessed using a five point scale ranging from 1 (very low) to 5 (very high). Intentions for smoking were also assessed with the question, "Do you think you will be smoking cigarettes this time next year?". Response options ranged from 1 (no chance of smoking) through to 7 (certain to be smoking). This established measure ${ }^{33}$ has been found to have high test-retest reliability. ${ }^{34}$

The post-film questionnaire included further items assessing perceptions of business conduct by the tobacco industry and other industries. Subjects were required to rate the extent to which they agreed or disagreed with a series of statements about the tobacco industry and other industries on a five point Likert scale where 1 equals "strongly agree" and 5 equals "strongly disagree". Multiple choice items were used to assess perceptions of smoking prevalence in "real life" and in films compared to real life.

PROCEDURE

Field workers approached cinema patrons in the foyer before screenings of the respective films and explained that the Anti-Cancer Council of Victoria was doing a survey of people's reactions to The Insider and Erin Brockovich. Patrons were asked whether they were seeing the target film. If they answered "yes", the field worker explained the procedures (including an assurance of the confidentiality of their answers), and invited the person to participate in the survey in exchange for a free cinema ticket to be provided after completion of the post-test. Consenting subjects completed an informed consent form and the pre-film questionnaire in the cinema foyer. They then watched the film as they normally would.

Surveying was conducted during the films' first week of release in Melbourne cinemas. To obtain sufficient sample size, recruiting was carried out over five nights for The Insider (27 January to 1 February 2000) and three nights for Erin Brockovich (13-15 April 2000); the differing dates reflect the respective release dates. There were sufficient numbers of field workers on duty that all people who entered the foyer were approached-very few eligible subjects declined to participate.

Two days post-viewing, field workers began telephoning subjects regarding the post-film survey. Subjects who completed the post-film survey were posted a free cinema ticket. The mean (SD) time delay between seeing the film and completing the post-film questionnaire was 11.08 (7.74) days.

\section{ANALYSIS}

The data were analysed using SPSS. Data were missing on less than $2 \%$ of cases for all variables, except the measures of subjects' ratings of different professions where it was up to $5 \%$ of cases. This appeared to be caused by confusion over the question format. A significance level of $\mathrm{p}<0.05$ is accepted throughout.

The mean number of days taken for successful follow up was less for The Insider subjects 
$(\bar{x}=8.72, \mathrm{SD}=6.26)$ than Erin Brockovich subjects $\quad(\bar{x}=14.33, \quad \mathrm{SD}=8.41$, $\mathrm{t}(264)=-6.24, \mathrm{p}<0.001)$. Owing to the potential confound of time taken to complete the post-film questionnaire, the multivariate analyses assessing attitudes toward smoking and the tobacco industry were also performed selecting those cases who completed their follow-up survey within two weeks of seeing the film. For the analyses of attitudes toward the tobacco industry and other industries comparable effects for film condition were found, so the results are reported for all cases. However for the analyses of intentions to smoke, results differed when late responders were excluded; details are reported.

For the items assessed at pre- and post-film, MANCOVAs (multivariate analyses of covariance) were used, with movie condition as a between subjects factor and time as a within subjects factor. Smoking status, age group, education level, and sex were covariates. The nominal measure of smoking status was collapsed into a binary dummy variable, where $1=$ current smoker $(22.5 \%)$ and $2=$ non-smoker $(77.5 \%)$. To correct skewness, education was collapsed into two categories: those with a university or college degree $(55 \%)$ and those with lower levels of education (45\%).

For the items assessed at post-film only, hierarchical regression analyses were performed. The independent variables entered simultaneously in the first block were sex, age, education, smoking status, and pre-film ratings of a tobacco industry executive for ethics and honesty, and power. The binary measures of smoking status and education were used. For the regressions with post-film measures of attitudes to the tobacco and other industries as dependent variables, film condition was added to the equation in the second block. For the regression analysis assessing the impact of frequency of movie consumption on perceptions of "real life" smoking prevalence, an index of frequency of movie viewing was added to the equation in the second block. The index was the sum of the frequency with which subjects reported watching movies on television, at the cinema and on video (as per the seven point indices).

\section{Results}

PERCEPTIONS OF DIFFERENT PROFESSIONS

At pre-film "Nurse" received the highest mean rating for "ethics and honesty" $(\bar{x}=4.10, S D=$ $0.79)$ and "tobacco industry executive" received the lowest $(\bar{x}=1.77, \mathrm{SD}=0.87)$. The mean score for "tobacco industry executive" was significantly lower than for "politician" $(\bar{x}=2.12, \quad S D=0.88)$, the next lowest $(t(308)=6.02, p<0.001)$. An approximately reverse pattern was found for "power" with nurse receiving the lowest rating pre-film $(\bar{x}=2.43, \mathrm{SD}=1.10)$. Politician $(\bar{x}=4.10$, $\mathrm{SD}=0.98)$ followed by tobacco industry executive $(\bar{x}=3.58, \mathrm{SD}=1.08)$ received the highest power ratings $(\mathrm{t}(308)=8.53$, $\mathrm{p}<0.001)$.

CHANGES IN RATINGS OF A TOBACCO INDUSTRY EXECUTIVE AS A FUNCTION OF FILM VIEWING For the "ethics and honesty" MANCOVA, the combined effect of the covariates was significant, $F(4,242)=3.09, p=0.016$. Smokers tended to rate a tobacco industry executive higher on ethics and honesty than nonsmokers, $\mathrm{t}(242)=-2.915, \mathrm{p}=0.004$. A main effect of film $(\mathrm{F}(1,242)=5.31, \mathrm{p}=0.022)$ revealed that The Insider subjects tended to rate a tobacco industry executive as lower on ethics and honesty compared to Erin Brockovich subjects at pre- $(\bar{x}=1.68 v \bar{x}=1.78)$ and post-film $(\bar{x}=1.63 \quad v \quad \bar{x}=1.90)$ $(t(242)=-2.305, p=0.022)$. There was no significant main effect of time $(F(1,246)=$ $0.35, \mathrm{p}=0.553)$ nor interaction between film viewed and time $(\mathrm{F}(1,246)=2.07, \mathrm{p}=0.151)$, although the direction of the trend was for the difference between The Insider and Erin Brockovich subjects to be greater after film viewing.

For "power" the combined effect of the covariates was not significant $(\mathrm{F}(4,241)=2.14$, $\mathrm{p}=0.077)$. A main effect of film $(\mathrm{F}(1,241)=5.61, \mathrm{p}=0.019)$ revealed that The Insider subjects tended to rate a tobacco industry executive as higher on power compared to Erin Brockovich subjects at pre- $(\bar{x}=3.72 v$ $\bar{x}=3.54)$ and post-film $(\bar{x}=3.96 v \bar{x}=3.72)$ $(t(241)=2.368, p=0.019)$. There was $a$ significant main effect of time $(\mathrm{F}(1,245)=9.25, \mathrm{p}=0.003)$ but no significant interaction between film viewed and time $(\mathrm{F}(1,245)=0.14, \mathrm{p}=0.707)$, although the direction of the trend was for the difference between The Insider and Erin Brockovich subjects to be greater after film viewing. Irrespective of film viewed, subjects tended to rate a tobacco industry executive as higher on power at post-film than at pre-film $(t(241)=-3.041, p=0.003)$. A main effect of time also occurred for the MANCOVA on ratings of a multinational food company executive for power $(F(1,242)=9.41, p=0.002)$.

Table 3 Mean level of disagreement ( $1=$ strongly agree, $5=$ strongly disagree) with statements about tobacco companies aand other industries for subjects who saw The Insider and Erin Brockovich

\begin{tabular}{|c|c|c|}
\hline Statement & $\begin{array}{l}\text { The Insider } \\
\text { Mean (SD) } n=154\end{array}$ & $\begin{array}{l}\text { Erin Brockovich } \\
\text { Mean (SD) } n=107\end{array}$ \\
\hline (a) Tobacco companies have freely provided information on the health risks of smoking & $3.91(1.17)$ & $3.32(1.24)$ \\
\hline (b) Tobacco companies make a positive contribution to the community through sponsorship of sport and cultural activities & $3.83(1.15)$ & $3.47(1.16)$ \\
\hline (c) Commercial news media gives accurate information on current affairs & $3.30(1.14)$ & $3.24(1.20)$ \\
\hline (d) Tobacco companies have every right to sell their products while they are legal & $2.41(1.01)$ & $2.32(0.85)$ \\
\hline (e) Tobacco companies behave in socially irresponsible ways & $1.99(1.05)$ & $2.09(0.94)$ \\
\hline (f) When big companies are involved, news media aren't always free to present things as they are & $1.89(0.81)$ & $2.20(0.83)$ \\
\hline (g) Tobacco companies distort the truth about smoking so more people smoke & $1.84(0.92)$ & $2.34(0.98)$ \\
\hline (h) Tobacco companies will stop at nothing to sell their products & $1.82(0.88)$ & $2.17(1.01)$ \\
\hline (i) There should be greater penalties for companies whose products cause sickness or death & $1.62(0.80)$ & $1.75(0.87)$ \\
\hline
\end{tabular}


POST-FILM INDUSTRY ATTITUDES

Table 3 lists subjects' mean scores on the post-film items assessing level of agreement with statements about the tobacco industry and other industries, for the two conditions. Subjects in both conditions tended to disagree with the positively worded statements about the tobacco industry ( $a$ and $b$ ) and agree with the negatively worded statements about the industry $(e, g$, and $h)$.

Principal components analysis was performed on the items on the tobacco industry. Two factors were extracted. The first factor based subscale measured "perceptions of business conduct by the tobacco industry" (items $a, e, g$, and $h$; factor loadings from \pm 0.46 to 0.74 ) and the second measured "community acceptance of the tobacco industry" (items $b$ and $d$; factor loadings 0.76 and 0.78 ).

An index of perceptions of business conduct by the tobacco industry was created by computing the mean of items $a, e, g, h$ (Cronbach's $\alpha=0.62 ; \bar{x}=2.09, \mathrm{SD}=0.73)$. Scores on the positively worded item (a) were reversed to make them comparable to the other negatively worded statements. For the regression analysis, more negative views of business conduct by the tobacco industry were associated with being older $(\mathrm{F}(7,236)=4.53, \mathrm{p}=0.034)$, a nonsmoker $(\mathrm{F}(7,236)=6.87, \mathrm{p}=0.009)$, rating tobacco industry executive as low on "ethics and honesty" $(\mathrm{F}(7,236)=15.83, \mathrm{p}<0.001)$ and high on "power" $(\mathrm{F}(7,236)=5.24$, $\mathrm{p}=0.023)$ at pre-film. People who saw The Insider tended to hold more negative views of business conduct by the tobacco industry $(\mathrm{F}(7,236)=14.98, \mathrm{p}<0.001)$-film condition added an increment of 5\% to explanation of the dependent variable.

An index of community acceptance of the tobacco industry was created by computing the mean of items $b$ and $d$ (Cronbach's $\alpha=0.43$; $\bar{x}=3.02, \quad S D=0.85)$. For the regression analysis, weaker community acceptance of the tobacco industry was associated with being younger $(\mathrm{F}(7,235)=6.09, \mathrm{p}=0.014)$, and rating a tobacco industry executive as lower on "ethics and honesty" pre-film $(\mathrm{F}(7,235)=7.97, \mathrm{p}=0.005)$. People who saw The Insider tended to show less community acceptance of the tobacco industry $(\mathrm{F}(7,235)=6.22, \mathrm{p}=0.013)$-film condition added an increment of $2 \%$ to explanation of the dependent variable.

The non-tobacco industry items were analysed individually, owing to low reliability of composite measure. People who saw The Insider $(\mathrm{F}(7,233)=10.04, \mathrm{p}=0.002)$ and smokers $(\mathrm{F}(7,233)=4.51, \mathrm{p}=0.035)$ were more likely to agree with the statement "when big companies are involved, news media aren't always free to present things as they are"-film condition added an increment of $4 \%$ to explanation of the dependent variable. There were no effects for the covariates or film condition on responses to the statements "Commercial news media gives accurate information on current affairs" and "There should be greater penalties for companies whose products cause sickness or death".
INTENTIONS TO SMOKE

To assess whether the films had an impact on intentions for smoking, we performed MANCOVA on subjects' pre and post-film intention scores for those who completed their follow up survey within two weeks of seeing the film, as we assumed any effects of the films on intentions were likely to be short term. The combined effect of the covariates was significant $(\mathrm{F}(4,188)=114.97, \mathrm{p}<0.001)$. As would be expected, current smokers reported stronger intentions to smoke in future than non-smokers $(t(188)=-21.11, p<0.001)$. There were no significant effects for age group $(p=0.070), \quad$ education $\quad(p=0.934), \quad$ sex $(\mathrm{p}=0.269)$ or main effects for time $(\mathrm{F}(1,192)=0.46, \quad \mathrm{p}=0.498)$ and film $(\mathrm{F}(1,188)=0.62, \mathrm{p}=0.431)$. However, there was a significant interaction between film and time, with subjects who saw The Insider showing a decline in intentions at post-film (pre-film: $\bar{x}=1.97, \quad \mathrm{SD}=1.57$; post-film: $\bar{x}=1.76, S D=1.44$ ), and a divergent trend for Erin Brockovich subjects (pre-film: $\bar{x}=1.75, \quad \mathrm{SD}=1.55 ; \quad$ post-film: $\quad \bar{x}=1.86$, $\mathrm{SD}=1.80)(\mathrm{F}(1,192)=4.63, \mathrm{p}=0.03)$. The trend of decline in intentions among Insider subjects occurred for current smokers (pre: $\bar{x}=3.94$, post: $\bar{x}=3.75$ ), ex-smokers (pre: $\bar{x}=2.18$, post: $\bar{x}=1.41$ ), and non-smokers (pre: $\bar{x}=1.16$, post: $\bar{x}=1.05$ ). When the MANCOVA was performed with late responders included, the interaction between time and film was not significant $(\mathrm{F}(1,259)=3.38$, $p=0.067)$.

PERCEPTIONS OF SMOKING PREVALENCE

For the question, "Do you think more people smoke in films than in real life?", $52 \%$ answered "No, fewer people smoke in films than in real life", $22 \%$ answered "No, a similar number of people smoke in films and in real life", $17 \%$ answered "Yes, more people smoke in films than in real life", and 9\% answered "Not sure".

For the question, "In Australia, do you think smoking is less or more common than it was 10 years ago?", 43\% answered "Less common, fewer people smoke these days", $13 \%$ answered "About the same", 34\% answered "More common, more people smoke these days", and $10 \%$ were "Not sure". The first three response categories were treated as a three level dependent variable for the regression analysis. Higher perceptions of smoking prevalence in real life were associated with lower educational status $(\mathrm{F}(7,211)=8.09, \mathrm{p}=0.005)$, and watching movies more frequently $(\mathrm{F}(7,211)=13.87$, $\mathrm{p}<0.001)$.

\section{Discussion}

ATTITUDES TO THE TOBACCO INDUSTRY

Steve Kottak, a spokesman for Brown and Williamson in the USA, is quoted as saying of The Insider: "We regard ourselves as an ethical company and a responsible company. This movie has set us back in that regard". ${ }^{24}$ However our results indicate that before viewing the films, people's perceptions of the ethics 
and honesty of a tobacco industry executive were low relative to other professions. These findings parallel those of another Australian survey. ${ }^{25}$ As far as the movie promoting a more negative perception of the ethics of the tobacco industry goes, there was little room to move. People's baseline attitudes to the industry made a significant contribution to explaining their attitudes to the industry at post-film.

Erin Brockovich had parallels with The Insider, in that a major plot element was about a large business covering up the health impact of their products on the community. Our results suggest both films may have promoted a generalised perception of the power of big business, and subjects in both conditions showed similar agreement with the statement "there should be greater penalties for companies whose products cause sickness or death" at post-film.

While the viewing The Insider only accounted for a small (but significant) proportion of the variance in the dependent variables assessing attitudes toward the tobacco industry at post-film, it should be remembered that the effects observed are the result of a single exposure to anti-tobacco content in a movie. A study that captured the cumulative effects of repeated exposure to negative (or positive) depictions could be expected to show more substantial and lasting change. We found that the post-film survey items that focused on content specific to The Insider tended to elicit differences between viewing conditions. Subjects who saw The Insider tended to hold more negative perceptions of business conduct by the tobacco industry and show less community acceptance of the tobacco industry at post-film than those who saw Erin Brockovich. Another issue that received considerable attention in The Insider (but not Erin Brockovich) was that of news media bowing to pressure from big business. People who saw The Insider tended to agree more strongly that "when big companies are involved, news media aren't always free to present things as they are".

INTENTIONS FOR SMOKING

A most interesting finding is that The Insider may have promoted a reduction in intentions to smoke in the future among subjects that persisted for up to two weeks. Compared to the barrage of positive smoking images in films, The Insider represents a drop in the ocean. Yet the presence of this small effect for intentions suggests that if people were more recurrently exposed to anti-tobacco content in movies there may be potential for a more substantial and lasting cumulative impact on attitudes toward smoking. Our survey was of people aged 15 and over, who self selected to see this film. It would be of interest to assess whether this film would promote an anti-smoking message to adolescents, who continue to be a challenging group to influence not to smoke. Evaluation results for anti-tobacco industry campaigns in the USA suggest that demonisation of the tobacco industry may be effective at promoting an anti-smoking message to youth audiences. ${ }^{19} 20$

\section{What this paper adds}

Concerns have been raised about the role pro-tobacco images in movies may play in promoting smoking. This paper explores audience response to a movie containing anti-tobacco content-The Insider. Results suggest that the versatile and popular medium of film also has the potential to promote an anti-smoking message when tobacco is presented in a negative light.

PERCEPTIONS OF SMOKING PREVALENCE

While people may be influenced by depictions of actors smoking in films, ${ }^{11}$ our results indicate viewers may not attend to the frequency of these depictions. Contrary to content analysis showing elevated smoking prevalence in films ${ }^{13}$, a minority of subjects felt more people smoke in films than in real life. Cultivation theory predicts that people who consume a lot of media will hold perceptions of reality that reflect those of the media environment. ${ }^{35}$ In Australia, population smoking rates declined between 1989 and $1992,{ }^{36}$ stalled between 1992 and $1995,{ }^{37}$ then continued to decline. ${ }^{38}$ Smoking rates in popular movies increased during this period. ${ }^{3}$ We found that people who perceived "real world" smoking rates to have increased over the past 10 years watched movies more frequently than those who did not hold this perception. This finding points to the role movies may play in normalising smoking.

\section{STUDY LIMITATIONS}

A criticism of much past experimental media research is that the findings have limited ecological validity - viewers are often exposed to media "stimuli" which are stripped of their narrative and genre context and viewed in nonnatural conditions; responses are measured immediately after exposure. ${ }^{39}$ We were committed to surveying viewers who were seeing the movies for the first time, in a naturalistic setting, and monitoring more lasting attitude changes. It was not feasible to randomise subjects to the respective films as they were released at different times, and we aimed to study people's responses to films watched when and where the subjects chose.

A limitation of this quasi-experimental design is that the control group was non-equivalent. ${ }^{40}$ The within-subjects design gave us the capacity to conduct conservative statistical analyses controlling for observed pre-existing differences between subjects in the two film conditions, and effects for film condition still occurred. However, for the variables that were only assessed at post-film and differed as a function of film condition, we cannot be certain of the direction of causality of the correlations observed. It is possible that there were other important covariates that we failed to assess. For example, different viewers may have gravitated to the two films based on the way they were marketed. In Australian cinemas, a prominent US actress such as Julia Roberts may attract a subtly different crowd compared to Russell Crowe who is a male, 
New Zealand born star. Also promotions for The Insider mentioned a cover up story involving the tobacco industry, so viewers may have had some pre-conceived ideas about the industry before viewing the film.

CONCLUSIONS

Just as positive movie depictions of smoking may promote attitudes supportive of smoking, our results suggest the versatile and popular medium of film also has the potential to promote an anti-smoking message when tobacco is presented in a negative light. Film-makers are in a powerful position. No doubt their creativity is up to the challenge of producing more frequent depictions of the dark side of tobacco. On creative and ethical grounds, this approach would be more artful than regurgitating clichéd images of smoking as sexy, cool, or calming, which only perpetuate the mythology of tobacco advertising.

The authors thank the cinemas that hosted the study and the survey participants for their cooperation. We are also most grateful to Jason Boulter for his assistance in coordinating data collection.

Funding: National Health and Medical Research Council (Post-Graduate Scholarship) and The Anti-Cancer Council of Victoria.

1 Hazan AR, Lipton HL, Glantz SA. Popular films do not reflect current tobacco use. Am f Public Health 1994; 84:998-1001

2 Terre L, Drabman RS, Speer P. Health-relevant behaviors in media. F Applied Soc Psychol 1991;21:1303-19.

3 Stockwell TF, Glantz SA. Tobacco use is increasing in popular films. Tobacco Control 1997;6:282-4.

4 Hazan AR, Glantz SA. Current trends in tobacco use on prime-time fictional television. Am $\mathcal{f}$ Public Health 1995;85:116-7.

5 Everett SA, Schnuth RL, Tribble JL. Tobacco and alcohol use in top-grossing American films. F Community Health 1998;23:317-24.

6 McIntosh WD, Bazzini DG, Smith SM, et al. Who smokes in Hollywood? Characteristics of smokers in popular films

7 Escamilla G, Cradock AL, Kawachi I. Women and smoking in Hollywood movies: a content analysis. Am $\mathcal{F}$ Public in Hollywood movies:

8 Roberts D, Henriksen L, Christenson P. Substance use in popular movies and music. Washington: Office of Nationa Drug Control Policy and Department of Health and Human Services Substance Abuse and Mental Health Services Administration, 1999.

9 Goldstein AO, Sobel RA, Newman GR. Tobacco and alcohol use in G-rated children's animated films. $7 A M A 1999$ 281:1131-36.

10 Distefan J, Gilpin E, Sargent J, et al. Do movie stars encourage adolescents to start smoking? Evidence from California. Prev Med 1999;28:1-11.

11 Pechmann C, Shih C-F. Smoking scenes in movies and antismoking advertisements before movies: effects on youth. fournal of Marketing 1999;63:1-13.

12 Tickle JJ, Sargent JD, Dalton MA, Beach ML, Heatherton TF. Favourite movie stars, their tobacco use in contempoTF. Favourite movie stars, their tobacco use in contempo-
rary movies, and its association with adolescent smoking. raby movies, and its association

13 Gerbner G. Mass media discourse: message system analysis as a component of cultural indicators. In: van Dijk TA, ed. Discourse and communication: new approaches to the analysi of mass media discourse and communication. New York: Walter de Gruyter, 1985:13-25.

14 Rice RE, Atkin C. Principles of successful public communication campaigns. In: Bryant J, Zillman D, eds. Media effects: advances in theory and research. Hillsdale, New Jersey: Lawrence Erlbaum Associates: 1994:365-88.

15 Lima JC, Siegal M. The tobacco settlement: an analysis of newspaper coverage of a national policy debate, 1997-8. Tobacco Control. 1999;8:247-53.

16 Dyer C. Confidential tobacco documents enter public domain. BMF 1998;316:1186

17 Glantz SA. The truth about big tobacco in its own words. BMF 2000;321:313-4.

18 Glantz SA, Slade J, Bero LA, et al. The cigarette papers. Berkeley, California: University of California Press, 1996. Accessed 18 October 2000. URL: http:// www.library.ucsf.edu/tobacco/cigpapers/

19 Balbach ED, Glantz SA. Tobacco control advocates must demand high-quality media campaigns: the California

20 Zucker D, Hopkins RS, Sly DF, et al. Florida's "truth" campaign: a counter-marketing, anti-tobacco media campaign. $\exists$ Public Health Management Practice. 2000;6:1-6.

21 Givel MS, Glantz SA. Failure to defend a successful state tobacco control program: policy lessons from Florida. $A m$ f Public Health. 2000;90:762-7.

22 The Internet Movie Database (2001). Release dates for Insider, The. Accessed 9 January 2001. URL: http:// us.imdb.com/ReleaseDates?0140352

23 American Lung Association. (2000). Hackademy awards honor 'The Insider' for lighting into the tobacco industry. Press release dated 23 March 232000 , accessed 24 October 2000. URL: http://www.lungusa.org/press/association/ hackademy_2000.html

24 Poynter C. Brown and Williamson polling moviegoers: those who see 'Insider' asked for views of firm. Article from The Courier-fournal, 10 November 1999. Accessed 26 October 2000. URL: http://www.courier-journal.com/localnews/ 1999/9911/10/991110insi.html

25 Wakefield M, Miller C, Woodward S. Community perceptions about the tobacco industry and tobacco control funding. Aust NZ F Public Health 1999;23:240-4

26 Trotter L, Mullins R, Boulter J, et al. Key findings of the 1996 and 1997 household surveys. In: Trotter L, Mullins R. Quit evaluation studies number 9. Melbourne: The AntiCancer Council of Victoria, 1998:1-25.

27 Australian Bureau of Statistics. Australian social trends 2000. Catalogue No. 4102.0. Canberra: Australian Bureau of Statistics, 2000

28 Roy Morgan Research. Australian readership and product data: Fanuary 1997-December 1997. Melbourne: Roy Morgan Research, 1997.

29 Village Cinemas. The Insider: warning exposing the truth may be hazardous. Accessed 10 March 2000. URL: http:// cinema.village.com.au

30 Universal Studios. Erin Brockovich web site. Accessed 21 December 2000. URL: http://www.erinbrockovich.com

31 Commonwealth of Australia. Guidelines for the classification of films and videotapes. Sydney: Office of Film and Literature Classification, 1996.

32 Village Cinemas. Village cinemail registration form. Accessed 6 November 2000. URL: http://cinema.village.com.au/ cinemail/

33 Hill D, White V, Letcher T. Tobacco use among Australian secondary students in 1996. Aust NZ F Public Health 1999; 23:252-9.

34 Hill D, Willcox S, Gardner G, et al. Tobacco and alcohol use among Australian secondary school children. Med $\mathcal{F}$ Aust 1986;146:125-30.

35 Gerbner G, Gross L, Morgan M, et al. Growing up with television: the cultivation perspective. In: Bryant J, Zillman D, eds. Media effects: advances in theory and research. Hillsdale, New Jersey: Lawrence Erlbaum Associates, 1994:1742.

36 Hill D, White V. Australian adult smoking prevalence in 1992. Aust $\mathcal{F}$ Public Health 1995;19:305-8.

37 Hill D, White V, Scollo M. Smoking behaviours of Australian adults in 1995: trends and concerns. Med f Aust 1998; 168: 209-13

38 Tan N, Wakefield M, Freeman J. Changes associated with the national tobacco campaign: results of the second follow-up survey. In: Hasssard K, ed. Australia's national follow-up survey. In. Hasssard K, ed. Australia's national Commonwealth Department of Health and Aged Care, Australia, 2000:21-69.

39 Livingstone SM. Making sense of television: the psychology of audience interpretation. Potts Point, Australia: Pergamon Press, 1990.

40 Campbell DT, Stanley JC. Experimental and quasiexperimental designs for research. Chicago: Rand McNally, 1966. 